\title{
Effects of Haloperidol on Selective Attention A Combined Whole-Head MEG and High-Resolution EEG Study
}

\author{
Seppo Kähkönen, M.D., Ph.D., Jyrki Ahveninen, Ph.D., Iiro P. Jääskeläinen, Ph.D., \\ Seppo Kaakkola, M.D., Ph.D., Risto Näätänen, Ph.D., Juha Huttunen, M.D., Ph.D., \\ and Eero Pekkonen, M.D., Ph.D.
}

We used 122-channel magnetoencephalography (MEG) and 64-channel electroencephalogrphy (EEG) simultaneously to study the effects of dopaminergic transmission on human selective attention in a randomized, double-blind placebo-controlled cross-over design. A single dose of dopamine $D 2$ receptor antagonist haloperidol $(2 \mathrm{mg})$ or placebo was given orally to 12 righthanded healthy volunteers 3 hours before measurement. In a dichotic selective attention task, subjects were presented with two trains of standard ( $700 \mathrm{~Hz}$ to the left ear, 1,100 $\mathrm{Hz}$ to the right ear) and deviant (770 and $1,210 \mathrm{~Hz}$, respectively) tones. Subjects were instructed to count the tones presented to one ear; whereas, the tones presented to the other ear were to be ignored. Haloperidol significantly attenuated processing negativity $(P N)$, an event-related potential (ERP) component elicited by selectively attended standard tones at 300-500 ms after stimulus presentation. These results, indicating impaired selective attention by a blockade of dopamine D2 receptors, were further accompanied with increased mismatch negativity (MMN), elicited by involuntary detection of task-irrelevant deviants. Taken together, haloperidol seemed to induce functional changes in neural networks accounting for both selective and involuntary attention, suggesting modulation of these functions by dopamine $D 2$ receptors. [Neuropsychopharmacology 25:498-504, 2001] (C) 2001 American College of Neuropsychopharmacology. Published by Elseiver Science Inc.
From the BioMag Laboratory (SK,JA,EP), Medical Engineering Centre, Helsinki University Central Hospital, Helsinki, Finland; Cognitive Brain Research Unit (SK,JA,IPJ,RN,EP), Department of Psychology, University of Helsinki, Helsinki, Finland; Department of Neurology (JA,SK,EP), Helsinki University Central Hospital, Helsinki, Finland; Department of Clinical Neurophysiology (JH), Helsinki University Central Hospital, Helsinki, Finland; and Massachusetts General Hospital-NMR Center (IPJ), Harvard Medical School, Charlestown, Massachusetts.

Address correspondence to: Seppo Kähkönen, M.D., Ph.D., BioMag Laboratory, Medical Engineering Centre, Helsinki University Central Hospital, P.O. Box 340, FIN-00029 HUS, Finland. Tel.: +358 9 47175542; Fax: +3589 47175781. E-mail: seppo.kahkonen@ helsinki.fi

Received October 11, 2000; revised February 20, 2001; accepted March 7, 2001.

Online publication: 3/27/01 at www.acnp.org/citations/Npp 03270195 .
KEY WORDS: Auditory; D2 receptors; Electroencephalography (EEG); Haloperidol; Magnetoencephalography (MEG); Selective attention

Selective attention refers to the ability to attend to relevant information simultaneously ignoring irrelevant information (Posner and Boies 1971). The neural basis of selective attention can be noninvasively studied with high temporal resolution using event-related potentials (ERP) and magnetic fields (ERF), which are electroencephalogram (EEG) or magnetoencephalogram (MEG) changes time-locked to the presentation of external stimuli (Hari and Lounasmaa 1989; Näätänen et al. 1992). MEG and EEG detect slightly different aspects of 
the simultaneous electromagnetic brain activity; for example, localization of cerebral sources brain activity may be simpler and more accurate with MEG (Hämäläinen et al. 1993). However, EEG shows many attention-related components that are not clearly detected with MEG (Näätänen 1992). A simultaneous EEG and MEG recording, thus, provides high spatial and temporal resolution and makes it possible to differentiate neural events related to voluntary attention and involuntary perceptual processes.

During a dichotic listening task, the selectively attended task-relevant tones elicit the processing negativity $(\mathrm{PN})$, or a negative difference (Nd; Hansen and Hillyard 1988) potential between the ERPs to task relevant and irrelevant stimuli (Näätänen 1992). MEG studies of selective attention have, in turn, indicated that the amplitude of the N1m, elicited at about 100 ms poststimulus, is increased by selective attention, but the PN seems to be less visible for the MEG than EEG (Fujiwara et al. 1998). The mismatch negativity (MMN), or magnetic counterpart MMNm, is a pre-attentive ERP/ERF component elicited by any change in a sequence of frequent standard tones reflecting automatic detection and orientation to sudden environmental changes (Alho 1995; Näätänen 1992; Näätänen et al. 1978; Tiitinen et al. 1994).

Only a few studies have been devoted to drug effects on selective attention indexing by the PN. The NMDA receptor antagonist ketamine, alcohol, and adrenocorticotropic hormone (ACTH) have been shown to reduce PN (Smolnik et al. 1999; Hirvonen et al. 2000; Oranje et al. 2000). Opposite effects were observed after the administration of the antagonist of GABA receptors flumatzenil and cholecystokinin analog ceruletide (Schreiber et al. 1995; Smolnik et al. 1998). Anesthetic gas nitrous oxide $\left(\mathrm{N}_{2} \mathrm{O}\right)$ and adrenergic alpha 2-antagonist atipamezole had no effects on the PN (Mervaala et al. 1993; Pang and Fowler 1999). Shelley et al. (1997) studied effects of another adrenergic alpha 2-receptor agonist clonidine and dopamine D2 receptor antagonist droperidol on ERP indices of selective attention. They found that clonidine increased and droperidol decreased the PN.

Haloperidol is a potent, partially selective dopamine $\mathrm{D}_{2}$ receptor antagonist, which is widely used to treat psychotic disorders in clinical practice. Haloperidol affects spontaneous EEG activity, increasing slow waves and decreasing alpha and beta activity in healthy humans (McClelland et al. 1990). There is also evidence that haloperdiol decreases the transient $40 \mathrm{~Hz}$ response elicited by selectively attended tones (Ahveninen et al. 2000).

Our study was designed to investigate with simultaneous MEG and EEG recordings whether haloperidol, affects selective attention in healthy subjects.

\section{METHODS}

\section{Subjects and Procedure}

A randomized, double-blind, placebo-controlled, crossover design study with dopamine D2 receptor antagonist haloperidol (Serenase ${ }^{\circledR} 1 \mathrm{mg}$, Orion Pharma, Espoo, Finland) $2 \mathrm{mg}$ or placebo was performed. Drugs were orally given to 12 right-handed healthy volunteers (aged 20-28 years; six females) after informed written consent and institutional approval were obtained. Dosage was chosen in accordance with studies showing that $2 \mathrm{mg}$ of haloperidol affects cognitive performance without causing akathisia in healthy subjects (King 1994). The drugs were administered before $3 \mathrm{~h}$, because electrophysiological and positron emission tomagraphy (PET) data have shown that the effects peaked within 2 to 6 hours after haloperidol administration in normal subjects (Bartlett et al. 1994; Leigh et al. 1992; McClelland et al. 1990). The subjects were instructed to avoid alcohol for at least $48 \mathrm{~h}$, and caffeine and tobacco for $12 \mathrm{~h}$, before the recordings. The subjects reported having no history of neurologic or psychiatric disorders or using any drugs for 2 weeks before the study. None had been exposed to any class of neuroleptics previously. The hearing levels were confirmed by measuring the individual auditory thresholds. All experimental sessions were carried out between 0800 to 1200, and the sessions were separated by 1 week.

\section{Stimulus and Task}

The subjects were presented, dichotically through ear pieces and plastic tubes, with standard $(700 \mathrm{~Hz}$ to the left ear, $1,100 \mathrm{~Hz}$ to the right ear, $p=.44$ for each), and deviant $(770 \mathrm{~Hz}$ and $1,210 \mathrm{~Hz}$, respectively, $p=.06$ for each) $60 \mathrm{~ms}$ pure tones (with $5 \mathrm{~ms}$ rise and fall times) at $60 \mathrm{~dB}$ above the individually determined subjective hearing threshold. The interstimulus interval (ISI) randomly varied at 210 to $410 \mathrm{~ms}$. The subject task was to attend to the tones presented to one ear and to silently count the number of deviants, while ignoring tones presented to the other ear. The ear to be attended was counterbalanced across the subjects.

\section{Data Acquisition}

During the MEG and EEG recordings, each subject sat in a comfortable chair in a magnetically and electrically shielded room (Euroshield, Finland). The ERF and ERP were recorded with a 122 channel MEG (Neuromag, Finland; Ahonen et al. 1993) and 64-channel EEG (sampling rate $1 \mathrm{kHz}$ ) in each. Each two-channel sensor unit in MEG measured two independent magnetic field gradient components $\partial \mathrm{B}_{\mathrm{z}} / \partial \mathrm{x}$ and $\partial \mathrm{B}_{\mathrm{z}} / \partial \mathrm{y}$, the $\mathrm{z}$-axis being normal to the scalp. The position of the subject's head 
Table 1. Mean \pm SD Latencies and Amplitudes of Attended and Unattended P1m, N1m, N2m, MMNm and P3bm in the Haloperidol and Placebo Conditions

\begin{tabular}{|c|c|c|c|c|c|c|}
\hline Component & Condition & Hemisphere & $\begin{array}{c}\text { Haloperidol } \\
\text { Amplitude (fT/cm) }\end{array}$ & $\begin{array}{c}\text { Placebo } \\
\text { Amplitude (fT/cm) }\end{array}$ & $\begin{array}{l}\text { Haloperidol } \\
\text { Latency (ms) }\end{array}$ & $\begin{array}{c}\text { Placebo } \\
\text { Latency }(\mathrm{ms})\end{array}$ \\
\hline P1m & Attended & Right & $21.4 \pm 6.8$ & $20.9 \pm 7.7$ & $61.9 \pm 8.5$ & $59.8 \pm 10.7$ \\
\hline P1m & Attended & Left & $22.8 \pm 10.4$ & $27.2 \pm 12.8$ & $64.3 \pm 4.7$ & $59.6 \pm 9.6$ \\
\hline $\mathrm{P} 1 \mathrm{~m}$ & Unattended & Right & $20.2 \pm 9.9$ & $20.5 \pm 9.1$ & $65.1 \pm 8.9$ & $64.1 \pm 7.4$ \\
\hline $\mathrm{P} 1 \mathrm{~m}$ & Unattended & Left & $21.7 \pm 5.1$ & $23.9 \pm 10.2$ & $60.3 \pm 7.1$ & $60.2 \pm 10.1$ \\
\hline $\mathrm{N} 1 \mathrm{~m}$ & Attended & Right & $26.7 \pm 11.4$ & $25.9 \pm 9.5$ & $126.6 \pm 26.4$ & $113.1 \pm 34.2$ \\
\hline $\mathrm{N} 1 \mathrm{~m}$ & Attended & Left & $29.3 \pm 21.3$ & $34.1 \pm 20.7$ & $125.3 \pm 29.5$ & $126.2 \pm 27.1$ \\
\hline $\mathrm{N} 1 \mathrm{~m}$ & Unattended & Right & $22.1 \pm 9.2$ & $20.1 \pm 8.2$ & $135.2 \pm 27.4$ & $123.7 \pm 35.0$ \\
\hline $\mathrm{N} 1 \mathrm{~m}$ & Unattended & Left & $27.6 \pm 10.6$ & $28.9 \pm 11.6$ & $127.3 \pm 33.2$ & $120.7 \pm 30.2$ \\
\hline MMNm & & Right & $40.8 \pm 20.4$ & $30.8 \pm 14.2$ & $185.8 \pm 22.0$ & $183.3 \pm 38.7$ \\
\hline MMNm & & Left & $34.2 \pm 29.9$ & $21.1 \pm 7.6$ & $180.7 \pm 25.3$ & $179.4 \pm 41.3$ \\
\hline $\mathrm{N} 2 \mathrm{bm}$ & & Right & $33.8 \pm 13.7$ & $30.5 \pm 10.5$ & $181.1 \pm 35.9$ & $193.2 \pm 57.4$ \\
\hline $\mathrm{N} 2 \mathrm{bm}$ & & Left & $29.0 \pm 10.1$ & $23.0 \pm 11.3$ & $182.4 \pm 26.9$ & $179.9 \pm 47.8$ \\
\hline P3bm & & Right & $23.2 \pm 14.7$ & $17.2 \pm 6.3$ & $325.1 \pm 60.6$ & $317.9 \pm 63.7$ \\
\hline P3bm & & Left & $20.9 \pm 14.3$ & $18.3 \pm 7.8$ & $292.0 \pm 49.2$ & $324.0 \pm 77.0$ \\
\hline
\end{tabular}

relative to the recording instrument was determined by measuring the magnetic fields produced by marker coils in relation to cardinal points of the head (nasion, left and right preauricular points) that were determined before the experiment using an Isotrak 3D-digitizer (Polhemus, Colchester, VT, USA) (Ahlfors and Ilmoniemi 1989).

ERPs were recorded with an electrode cap (Virtanen et al. 1996) and an amplifier (Virtanen et al. 1997) specifically designed and built for simultaneous EEG and MEG measurements. The nose electrode was used as a reference. Vertical and horizontal electro-oculograms (EOG) were recorded. The locations of the EEG electrodes and the marker coils in relation to the cardinal points on the head were determined with the digitizer.

The recording passband was 0.03 to $100 \mathrm{~Hz}$ for EEG and MEG and 0.5 to $30 \mathrm{~Hz}$ for EOG. Digital bandpass filtering was performed off-line at 0.5 to $30 \mathrm{~Hz}$. The analysis period for averaged epochs was $750 \mathrm{~ms}$ (including a $50 \mathrm{~ms}$ prestimulus baseline). The first 20 responses and all the epochs coinciding with EOG, EEG, or MEG changes exceeding $100 \mu \mathrm{V}, 150 \mu \mathrm{V}$ or 3,000 fT/ $\mathrm{cm}$, respectively, were omitted from averaging. At least 100 artifact-free responses were averaged.

The distinct EPR/ERF peaks were obtained from latency ranges of 30 to $80 \mathrm{~ms}$ for $\mathrm{P} 1 / \mathrm{P} 1 \mathrm{~m}, 50$ to $150 \mathrm{~ms}$ for $\mathrm{N} 1 / \mathrm{N} 1 \mathrm{~m}, 150$ to $250 \mathrm{~ms}$ for P2/P2m, 150 to $400 \mathrm{~ms}$ for $\mathrm{N} 2 \mathrm{~b} / \mathrm{N} 2 \mathrm{bm}, 250$ to $700 \mathrm{~ms}$ for P3b/P3bm and P3a/ P3am, 130 to 250 for MMN/MMNm, and 100 to $700 \mathrm{~ms}$ for PN. The responses were judged significant when they were $>2 \times$ standard deviations (SD) of the prestimulus noise.

\section{Data Analysis}

The ERF peak latencies and amplitudes were measured from the channel pair showing the highest amplitude over the left and right temporal areas $\left(\left[\partial \mathrm{B}_{z} / \partial \mathrm{x}\right]^{2}+\left[\partial \mathrm{B}_{\mathrm{z}} /\right.\right.$ $\left.\partial y]^{2}\right)^{1 / 2}$. The sources of N1m and MMNm were further estimated with single equivalent current dipoles (ECD), found by a least-squares fit a fixed subset of 34 channels separately over each auditory cortex (Hämäläinen et al. 1993). Dipole fits with at most 30\% residual variance were considered successful. A spherical head model was

Table 2. Dipole Locations and Strength (Mean \pm SD) of MMNm and N1m after Haloperidol and Placebo Administrations

\begin{tabular}{|c|c|c|c|c|c|c|c|c|c|c|c|}
\hline \multirow[b]{2}{*}{ Component } & \multirow[b]{2}{*}{ Hemisphere } & \multicolumn{2}{|c|}{$x(\mathrm{~mm})$} & \multicolumn{2}{|c|}{$y(m m)$} & \multicolumn{2}{|c|}{$\mathrm{z}(\mathrm{mm})$} & \multicolumn{2}{|c|}{$Q$ (nAm) } & \multicolumn{2}{|c|}{$\mathrm{g}(\%)$} \\
\hline & & Hal & Placebo & Hal & Placebo & Hal & Placebo & Hal & Placebo & Hal & Placebo \\
\hline MMNm & Contralateral & $47 \pm 11$ & $44 \pm 15$ & $17 \pm 13$ & $24 \pm 12$ & $60 \pm 15$ & $58 \pm 16$ & $14 \pm 9$ & $24 \pm 37$ & 81 & 80 \\
\hline MMNm & Ipsilateral & $-45 \pm 12$ & $-45 \pm 10$ & $5 \pm 7$ & $13 \pm 11$ & $48 \pm 8$ & $60 \pm 12$ & $18 \pm 13$ & $13 \pm 8$ & 76 & 76 \\
\hline N1m (attended) & Contralateral & $47 \pm 9$ & $46 \pm 10$ & $15 \pm 17$ & $12 \pm 14$ & $65 \pm 10$ & $59 \pm 9$ & $12 \pm 8$ & $11 \pm 5$ & 89 & 88 \\
\hline N1m (attended) & Ipsilateral & $-49 \pm 8$ & $-47 \pm 10$ & $2 \pm 10$ & $-0.1 \pm 9$ & $67 \pm 12$ & $54 \pm 13$ & $8 \pm 4$ & $14 \pm 9^{*}$ & 88 & 91 \\
\hline N1m (unattend) & Contralateral & $50 \pm 9$ & $50 \pm 3$ & $14 \pm 15$ & $11 \pm 11$ & $63 \pm 64$ & $64 \pm 7$ & $10 \pm 5$ & $10 \pm 5$ & 90 & 92 \\
\hline N1m (unattend) & Ipsilateral & $-51 \pm 7$ & $-52 \pm 10$ & $5 \pm 19$ & $1 \pm 7$ & $50 \pm 19$ & $62 \pm 10$ & $18 \pm 31$ & $10 \pm 5$ & 88 & 92 \\
\hline
\end{tabular}

\footnotetext{
The $\mathrm{x}$-axis runs from left pre-aural point to the right. The $\mathrm{y}$-axis runs through the nasion, and $\mathrm{z}$-axis points upward. $\mathrm{Q}=$ dipole moment; $\mathrm{g}=\mathrm{good}-$ ness-of-fit; $n=$ number of subject modeled; ${ }^{*} p \leq .05$; paired $t$-test between haloperidol and placebo conditions.
} 
Table 3. Effects of Haloperidol and Placebo on ERPs (Mean \pm SD

\begin{tabular}{|c|c|c|c|c|c|}
\hline ERP deflection & Electrode & $\begin{array}{c}\text { Haloperidol } \\
\text { Amplitude }(\mu \mathrm{V})\end{array}$ & $\begin{array}{c}\text { Placebo } \\
\text { Amplitude }(\mu \mathrm{V})\end{array}$ & $\begin{array}{l}\text { Haloperidol } \\
\text { Latency (ms) }\end{array}$ & $\begin{array}{c}\text { Placebo } \\
\text { Latency (ms) }\end{array}$ \\
\hline P1 (attended) & $\mathrm{Cz}$ & $0.77 \pm 0.66$ & $0.67 \pm 0.66$ & $52 \pm 8.1$ & $50 \pm 9$ \\
\hline P1 (unattended) & $\mathrm{Cz}$ & $0.68 \pm 0.64$ & $0.55 \pm 0.68$ & $45 \pm 12$ & $49 \pm 16.3$ \\
\hline N1 (attended) & $\mathrm{Cz}$ & $-1.36 \pm 1.1$ & $-1.10 \pm 0.90$ & $111 \pm 17.8$ & $120 \pm 28$ \\
\hline N1 (unattended) & $\mathrm{Cz}$ & $-0.73 \pm 0.91$ & $-1.00 \pm 1.14$ & $108 \pm 20.0$ & $105 \pm 20.0$ \\
\hline P2 (attended) & $\mathrm{Cz}$ & $1.39 \pm 0.87$ & $1.40 \pm 0.73$ & $203 \pm 27$ & $221 \pm 23^{*}$ \\
\hline P2 (unattended) & $\mathrm{Cz}$ & $2.27 \pm 0.94$ & $2.29 \pm 1.43$ & $198 \pm 27$ & $195 \pm 25$ \\
\hline $\mathrm{MMN}$ & $\mathrm{FCz}$ & $-2.08 \pm 1.02$ & $-1.03 \pm 0.8^{*}$ & $190 \pm 52$ & $199 \pm 55$ \\
\hline $\mathrm{N} 2 \mathrm{~b}$ & $\mathrm{Cz}$ & $-3.10 \pm 1.44$ & $-1.98 \pm 1.82$ & $203 \pm 46$ & $206 \pm 44$ \\
\hline P3a & $\mathrm{Fz}$ & $0.64 \pm 1.90$ & $0.20 \pm 1.01$ & $302 \pm 43$ & $321 \pm 76$ \\
\hline $\mathrm{P} 3 \mathrm{~b}$ & $\mathrm{Pz}$ & $4.29 \pm 3.9$ & $5.75 \pm 4.5$ & $402 \pm 83$ & $418 \pm 99.7$ \\
\hline PN (100-300 ms) & $\mathrm{Fz}$ & $-0.61 \pm 0.9$ & $-0.75 \pm 0.7$ & & \\
\hline PN (300-500 ms) & $\mathrm{Fz}$ & $-0.21 \pm 0.9$ & $-0.83 \pm 0.9^{*}$ & & \\
\hline PN (500-700 ms) & $\mathrm{Fz}$ & $0.05 \pm 0.7$ & $-0.03 \pm 0.9$ & & \\
\hline
\end{tabular}

${ }^{*} p \leq .05$; paired $t$-test between haloperidol and placebo conditions.

used in the source modeling (Hämäläinen et al. 1993). The peak ERP peak amplitudes and latencies of the different components were measured from the channel where a given deflection was largest. The MMN and P3a for the unattended deviants were determined from substraction curves (deviant minus standard ERP, unattended channel). The MMN and P3a peak latencies and amplitudes were obtained at the electrode sites $\mathrm{CFz}$ and Fz. The N2b and P3b were determined for attended deviants from subtraction curves (deviant minus standard ERP, attended channel) at the electrode sites $\mathrm{Cz}$ and Pz. The PN was determined from substraction curves (standard ERP at attended channel minus standard ERP at unattended channel) at the electrode site Fz. The P1, N1, and $\mathrm{P} 2$ were determined from standard responses, at the $\mathrm{Cz}$.

The MEG data were analyzed with three-factor (drug $\times$ hemisphere $\times$ attended) repeated measures analyses of variance (ANOVAs). The EEG data analysis was carried out with permutation test for evaluating differences between potential maps (Karniski et al. 1994). Furthermore, the paired $t$-test was also used to detect differences of ERP data in the channel showing the strongest responses.

\section{RESULTS}

\section{MEG Results}

MEG results are summarized in Tables 1 and 2. The dipole moments $(\mathrm{Q})$ for $\mathrm{N} 100 \mathrm{~m}$ at the hemisphere ipsilateral to the stimulated ear in the attended, but not in the unattended, condition were significantly smaller after haloperidol administration ( $\mathrm{t}=-2.23 ; p=.05$ ) (Table 2). The dipole moments for $\mathrm{N} 100 \mathrm{~m}$ did not differ at the hemisphere contralateral to stimulated ear in the attended and unattended conditions after the haloperidol or placebo administration. Haloperidol did not affect the MMNm dipole moments.
No significant differences were found in the amplitudes and latencies of the $\mathrm{P} 1 \mathrm{~m}, \mathrm{~N} 1 \mathrm{~m}$, and $\mathrm{P} 2 \mathrm{~m}$ in the attended and unattended conditions. Furthermore, haloperidol did not affect the amplitudes and latencies of the MMNm, N2bm, and P3bm (Table 1). The source locations of the responses were not significantly influenced by haloperidol (Table 2).

\section{EEG Results}

Grand average unattended ERPs and PN are presented in Figures 1 and 2. All ERP data are summarized in Table 3. Haloperidol decreased PN, being significant in interval 300 to $500 \mathrm{~ms}$ only $(\mathrm{t}=-3.32 ; p<.05)$. Haloperidol significantly increased the amplitude of MMN ( $\mathrm{t}=$ $-3.02 ; p<.05)$ but no change was observed in its peak latency. The P2 latency for attended stimuli but not for unattended stimuli was shorter after the haloperidol administration $(\mathrm{t}=-2.62 ; p \leq .05)$. No differences were found in P2 amplitudes. Furthermore, no significant changes were detected in the P1 and N1 amplitudes or latencies in attended or unattended conditions after haloperidol administration. Nor did haloperidol affect the amplitudes and latencies of N2b, P3a, or P3b. Permutation test revealed no significant differences between administration of haloperidol and placebo in the potential maps of the P1, N1, and P2 amplitudes in the attended and unattended conditions or in amplitudes of MMN, $\mathrm{N} 2 \mathrm{~b}, \mathrm{P} 3 \mathrm{a}$, or P3b. However, the region with high-amplitude MMN response is much larger for haloperidol as compared with placebo (Figure 3).

\section{DISCUSSION}

MEG and EEG were used to determine the effects of an acute haloperidol challenge on selective attention in healthy subjects. Our results showed that a single low 


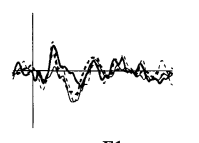

F1
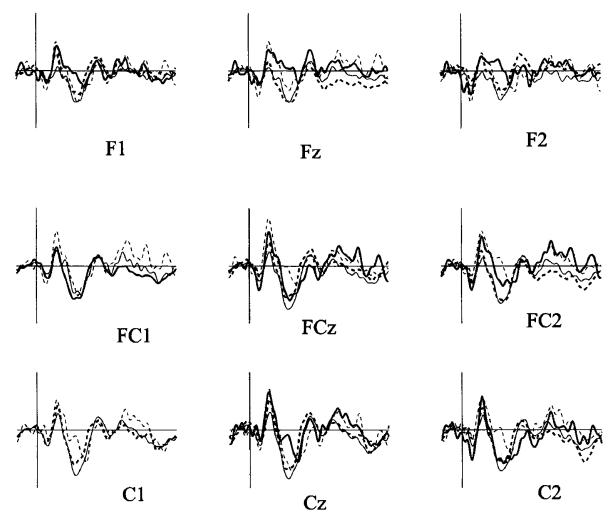

C1

$\mathrm{C} 2$
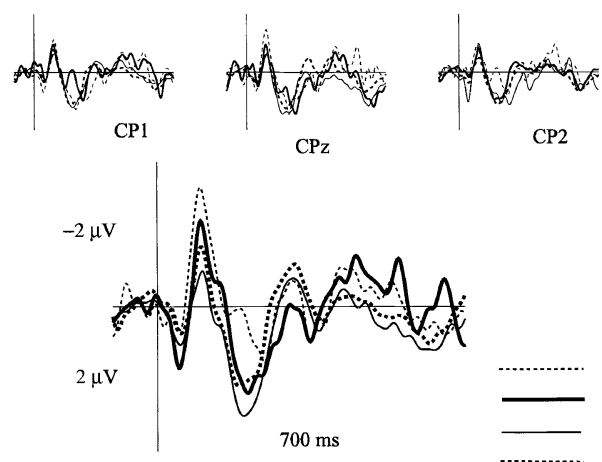

$\mathrm{CFz}$

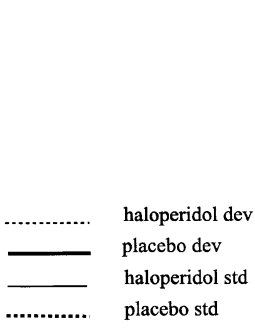

Figure 1. Grand averaged ERPs for the unattended condition after haloperidol (dotted lines) and placebo (solid lines) administration. The enlarged responses shown from frontocentral channel. Negativity is upward. Std = standard; dev = deviant.

dose of haloperidol (2 $\mathrm{mg}$ ) produced a specific pattern of changes in ERP and ERF components elicited by the tones presented to task-relevant and task-irrelevant ears. As for the attended tones, the PN amplitude and the ipsilateral N1m dipole strength decreased; whereas, the MMN to task-irrelevant deviants increased in amplitude. In principle, our data support the previous results of Shelley et al. (1997), who found that PN was reduced by droperidol, another antagonist of dopamine D2 receptors. The present result, however, provides novel information of the role played by the dopamine D2 receptors, because it is shown that droperidol has also antiadrenergic properties affecting cognitive functioning (Peroutka and Snyder 1980; Puumala et al. 1997); whereas, haloperidol is relatively devoid of them (Richelson and Nelson 1984). However, haloperidol is known to bind with high affinity to sigma receptors (Weisman et al. 1988). Therefore, it is possible that some of the observed effects in D2-poor areas reflect direct binding at nondopaminergic sites.

$\mathrm{PN}$ is identified with the negative difference between the ERPs to attended and to unattended stimuli, and it is supposed to be the electrophysiological correlate of selective attention (Näätänen 1982). Notably, haloperidol reduces glucose metabolism in the prefrontal
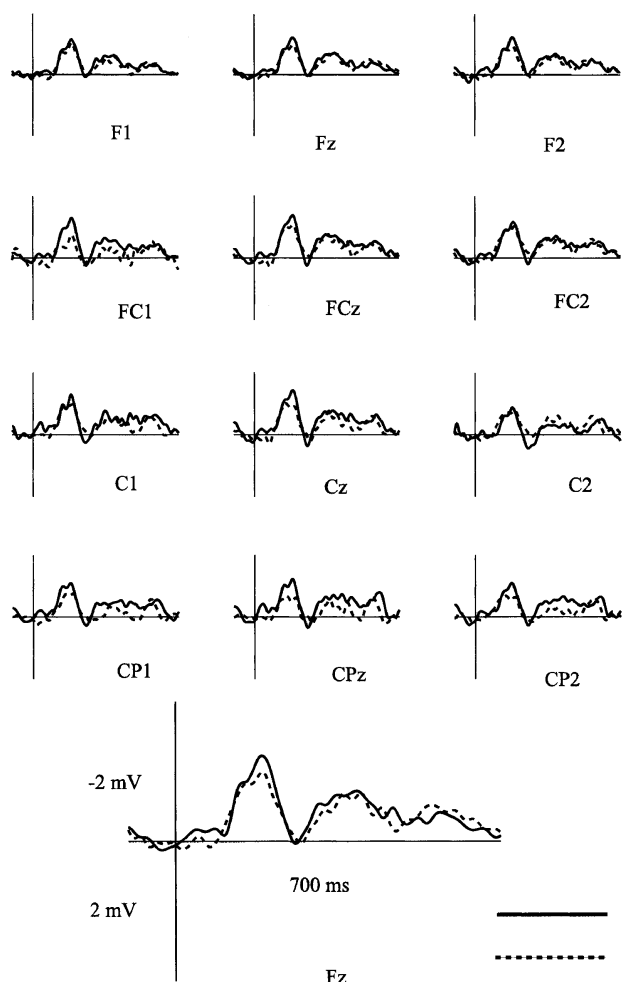

$\mathrm{CP}$

Figure 2. Grand averaged PN responses per lead for the haloperidol (dotted lines) and placebo condition (solid lines). The enlarged responses shown from frontal channel. Negativity is upward.

and anterior cingulate (Barlett et al. 1994). A recent PET study, using a dichotic-listening task resembling the present experimental setting, showed the same brain regions are activated by auditory selective attention (Kawashima et al. 1999). The present result of decreased PN could, thus, reflect haloperidol-induced impairment of regions that implicated in selective attention.

In addition, our results showed a significantly increased MMN, which reflects automatic stimuluschange detection. MMN is suggested to be composed of two subcomponents. The detection of a sound change is proposed to elicit the temporal MMN subcomponent and the subsequent involuntary attention shift to this sound change, is probably reflected by the later frontal MMN subcomponent (Alho 1995; Näätänen 1992; Rinne et al. 2000). The frontal subcomponent might be radially oriented, judging from the fact that it is not detected by MEG. Because MMNm was not significantly affected by haloperidol; whereas, MMN was, we might assume that the MMN augmentation might reflect the enhancement of frontal subcomponent. The MMN augmentation could, thus, be related to increased involuntary attention shifting to task-irrelevant channel, thus impairing the maintenance of concentration to the relevant task. One more explanation to MMN augmentation might be 

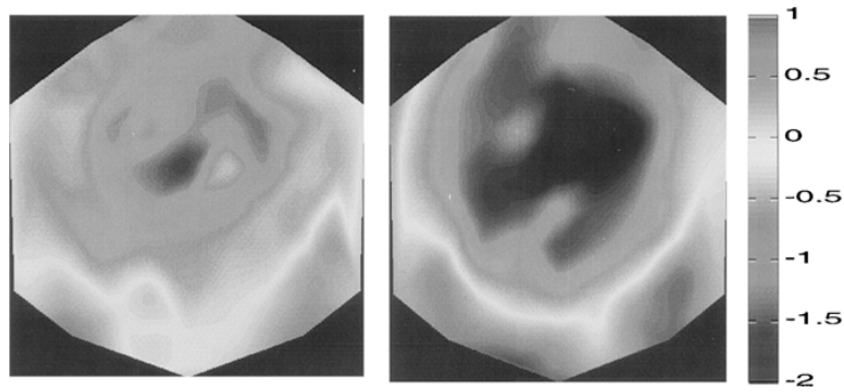

Figure 3. Grand-averaged potential maps of mismatch negativity (MMN) measured with 64-channel EEG after placebo (on the left) and haloperidol (on the right). Uppermost positions: frontal electrodes, lowermost: occipital

increased dopamine transmission followed after acute haloperidol administration (Lidsky and Banerjee 1993).

The N1 or N1m ERF waveforms were not significantly affected by haloperidol, which lends support to previous results (Abduljawad et al. 1999). This result is, futhermore, generally in line with the observations of Shelley et al. (1997) indicating no effects of droperidol in the audiory ERP elicited at 100 to $200 \mathrm{~ms}$ after stimulus onset. However, the present source modeling results indicated a significant reduction in dipole strength for N1m to attended stimuli in the ipsilateral hemisphere. This result was not supported by the ERF waveforms and contralateral N1m dipoles, nor by the PN analyzed during 100 to $200 \mathrm{~ms}$ poststimulus, and it, thus, must be interpreted cautiously. Tentatively, this effect might be related to attenuation of attentional modulation of the supratemporal N1m sources (Fujiwara et al. 1998) by haloperidol. Further studies on effects of haloperidol on N1m are clearly needed.

The different sensitivity of the EEG and the MEG to detect the changes of auditory components after haloperidol administration may partly explain why the effects were predominately detected in EEG. ERP might be partially constituted by deep sources, such as the subcortical sources that were affected by haloperidol (Barlett et al. 1994), are practically invisible to MEG, because the magnetic fields fall off more rapidly than the electric fields with increasing distance from the source. Furthermore, MEG detects only the tangential cortical sources (Hämäläinen et al. 1993), and, therefore, the electromagnetic activity in the fissures can be measured with MEG. EEG, in turn, detects certain aspects of the tangential sources, particularly the radial currents generated by in the cortical gyri. For example, the frontal brain regions might contribute to the signal recorded at the frontocentral leads. As already mentioned, haloperidol significantly reduced the activity in the frontal lobes (Barlett et al. 1994). Thus, we might assume that haloperidol primarily affected such attentional sources, either with radial orientation or deep origin, that are relatively invisible to MEG.

One further explanation to the differential sensitivity of auditory components to haloperidol may be linked to the different localization of $\mathrm{D}_{2}$ receptors in the auditory cortex. Recent histopathological studies showed that the majority of dopamine D2 receptors were located the lateral and inferior aspects of the superior temporal gyrus, less frequently on the lateral surface of the inferior temporal gyrus and the parahippocampal cortices, and were absent from the primary auditory cortex (Goldsmith and Joyce 1996). Consistent with this, the supratemporally generated ERFs (P1m, N1m, and $\mathrm{MMNm}$ ) in our study were not affected by haloperidol, the only trend being observed in the ipsilateral dipole for N1m to attended tones.

In conclusion, our results show that MEG and EEG have different sensitivity to auditory components after haloperidol administration showing the importance of measuring both MEG and EEG in neuropharmacological studies. In addition to these, dopamine $\mathrm{D}_{2}$ receptors modulate selective attention.

\section{ACKNOWLEDGMENTS}

This work was supported by the Finnish Cultural Foundation, Helsinki University Central Hospital Research Funds, the Ella and Georg Ehrnrooth's Foundation, and the Academy of Finland. We thank Mrs. Suvi Heikkilä and Mr. Teemu Peltonen for their excellent technical assistance.

\section{REFERENCES}

Abduljawad KA, Langley RW, Bradshaw CM, Szabadi E (1999): Effects of bromocriptine and haloperidol on prepulse inhibition: comparison of the acoustic startle eye-blink response and the N1/P2 auditory-evoked response in man. J Psychopharmacol 13:3-9

Ahlfors S, Ilmoniemi RJ (1989): Magnetometer position indicator for multichannel MEG. In Williamson SJ, Hoke M, Romani GL (eds), Advances in Biomagnetism. New York: Plenum Press, pp 673-676

Ahonen AI, Hämäläinen MS, Kajola MJ, Knuutila JE, Laine PP, Lounasmaa OV, Parkkonen LT, Simola JT, Tesche CD (1993): 122-channel SQUID instrument for investigating the magnetic signals from the human brain. Physica Scripta T49:198-205

Alho K (1995): Cerebral generators of mismatch negativity $(\mathrm{MMN})$ and its magnetic counterpart (MMNm) elicited by sound changes. Ear \& Hearing 16:38-51

Ahveninen J, Kähkönen S, Tiitinen H, Pekkonen E, Huttunen J, Kaakkola S, Ilmoniemi RJ, Jääskeläinen IP (2000): Suppression of transient $40-\mathrm{Hz}$ auditory response by haloperidol suggests modulation of human selective attention by dopamine D2 receptors. Neurosci Lett 292:29-32 
Bartlett EJ, Brodie JD, Simkowitz P, Dewey SL, Rusinek H, Wolf AP, Fowler JS, Volkow ND, Smith G, Wolkin A, Cancro R (1994): Effects of haloperidol challenge on regional cerebral glucose utilization in normal human subjects. Am J Psychiat 151:681-686

Goldsmith SK, Joyce JN (1996): Dopamine D2 receptors are organized in bands in normal human temporal cortex. Neuroscience 74:435-451

Hämäläinen M, Hari R, Ilmoniemi RJ, Knuutila J, Lounasmaa OV (1993): Magnetoencephalography-theory, instrumentation, application to noninvasive studies of working brain. Rev Mod Phys 65:413-498

Hansen JC, Hillyard SA (1988): Temporal dynamics of human auditory selective attention. Psychology 25:316-329

Hari R, Lounasmaa OV (1989): Recording and interpretation of cerebral magnetic fields. Science 244:432-436

Hirvonen J, Jääskeläinen IP, Näätänen $R$, Sillanaukee P (2000): Adenosine A1/A2a receptors mediate suppression of mismatch negativity by ethanol in humans. Neurosci Lett 278:57-60

Fujiwara N, Nagamine T, Imai M, Tanaka T, Shibasaki H (1998): Role of the primary auditory cortex in auditory selective attention studied by whole-head neuromagnetometer. Brain Res Cog Brain Res 7:99-109

Karniski W, Blair RC, Snider AD (1994): An exact statistical method for comparing topographic maps, with any number of subjects and electrodes. Brain Topogr 6:203-210

Kawashima R, Imaizumi S, Mori K, Okada K, Goto R, Kiritani S, Ogawa A, Fukuda H (1999): Selective visual and auditory attention toward utterances-a PET study. NeuroImage 10:209-215

King DJ (1994): Psychomotor impairment and cognitive disturbances induced by neuroleptics. Acta Psych Scand 380(Suppl.380):53-58

Leigh TJ, Link CGG, Fell GL (1992): Effects of granisetron and haloperidol, alone and in combination, on psychometric performance and the EEG. Br J Clin Pharmacol 34:65-70

Lidsky TI, Banerjee SP (1993): Acute administration of haloperidol enhances dopaminergic transmission. J Pharmacol Exp Ther 265:1193-1198

McClelland GR, Cooper SM, Pilgrim AJ (1990): A comparison of the central nervous system effects of haloperidol, chlopromazine, and sulpride in normal volunteers. Br J Clin Pharmacol 30:795-803

Mervaala E, Alhainen K, Helkala EL, Partanen J, Jousmäki V, Väyrynen M, Heinonen E, Riekkinen P (1993): Electrophysiological and neuropsychological effects of a central alpha 2-antagonist atipamezole in healthy volunteers. Behav Brain Res 55:85-91

Näätänen R, Gaillard AWK, Mäntysalo S (1978): Early selective-attention effect on evoked potential reinterpreted. Acta Psych 42:313-329

Näätänen R (1982): Processing negativity: an evoked-potential reflection of selective attention. Psych Bull 92:605-640

Näätänen R, Teder W, Alho K, Lavikainen J (1992): Auditory attention and selective input modulation: a topographical ERP study. NeuroReport 3: 493-496

Näätänen R (1992): Attention and brain function. Mahwah, New Jersey: Lawrence Erlbaum Associates

Oranje B, van Berckel BN, Kemner C, van Ree JM, Kahn RS, Verbaten MN (2000): The effects of a subanesthetic dose of ketamine on human selective attention. Neuropsychopharmacology 22:293-302

Pang EW, Fowler B (1999): Dissociation of the mismatch negativity and processing negativity attentional waveforms with nitrous oxide. Psychophysiology 36:552-558

Peroutka SJ, Snyder SH (1980): Relationship of neuroleptic drug effects at brain dopamine, serotonin, alpha-adrenergic, and histamine receptors to clinical potency. Am J Psychiat 137:1518-1522

Posner MI, Boies SJ (1971): Components of attention. Psychol Rev 78:391-408

Puumala T, Riekkinen P Sr, Sirvio J (1997): Modulation of vigilance and behavioral activation by alpha-1 adrenoceptors in the rat. Pharmacol Biochem Behav 56:705-712

Richelson E, Nelson A (1984): Antagonism by neuroleptics of neurotransmitter receptors of normal human brain in vitro. Eur J Pharmacol 103:197-204

Rinne T, Alho K, Ilmoniemi RJ, Virtanen J, Näätänen R (2000): Separate time behaviors of the temporal and frontal MNN sources. NeuroImage 12:14-19

Schreiber H, Stolz-Born G, Pietrowsky R, Kornhuber HH, Fehm HL, Born J (1995): Improved event-related potential signs of selective attention after the administration of the cholecystokinin analog ceruletide in healthy persons. Biol Psychiat 37:702-712

Shelley AM, Catts SV, Ward PB, Andrews S, Mitchell P, Michie P, McConaghy N (1997): The effect of decreased catecholamine transmission on ERP indices of selective attention. Neuropsychopharmacology 16:202-210

Smolnik R, Pietrowsky R, Fehm HL, Born J (1998): Enhanced selective attention after low-dose administration of the benzodiazepine antagonist flumazenil. J Clin Psychopharmacol 18:241-247

Smolnik R, Molle M, Fehm HL, Born J (1999): Brain potentials and attention after acute and subchronic intranasal administration of ACTH 4-10 and desacetyl-alpha-MSH in humans. Neuroendocrinology 70:63-72

Tiitinen H, May P, Reinikainen K, Näätänen R (1994): Attentive novelty detection in humans is governed by preattentive sensory memory. Nature 372:90-92

Virtanen J, Parkkonen L, Ilmoniemi RJ, Pekkonen E, Näätänen R (1997): Biopotential amplifier for simultaneous operation with biomagnetic instruments. Med Biol Engin Com 35:402-408

Virtanen J, Rinne T, Ilmoniemi RJ, Näätänen R (1996): MEGcompatible multichannel EEG electrode array. Electroenceph Clin Neurophysiol 99:568-570

Weisman, AD, Su TP, Hedreen JC, London ED (1988): Sigma receptors in post-mortem human brains. J Pharmacol Exp Ther 247:29-33 